Article

\title{
The in Vitro and in Vivo Degradation of Cross-Linked Poly(trimethylene carbonate)-Based Networks
}

\author{
Liqun Yang ${ }^{1,2,3}$, Jianxin $\mathrm{Li}^{1,2}$, Miao $\mathrm{Li}^{1,2}$ and Zhongwei Gu ${ }^{3, *}$ \\ 1 Key Laboratory of Reproductive Health and Medical Genetics, \\ National Health and Family Planning Commission, Shenyang 110031, China; yanglq@lnszjk.com.cn (L.Y.); \\ jxinl@vip.sina.com (J.L.); limiao_lnszjk@163.com (M.L.) \\ 2 Key Laboratory of Reproductive Health, Liaoning Research Institute of Family Planning, \\ Shenyang 110031, China \\ 3 National Engineering Research Center for Biomaterials, Sichuan University, Chengdu 610064, China \\ * Correspondence: zwgu@scu.edu.cn; Tel.: +86-28-8541-0336
}

Academic Editor: Jianxun Ding

Received: 18 March 2016; Accepted: 14 April 2016; Published: 19 April 2016

\begin{abstract}
The degradation of the poly(trimethylene carbonate) (PTMC) and poly(trimethylene carbonate-co- $\varepsilon$-caprolactone) (P(TMC-co-CL)) networks cross-linked by 0.01 and $0.02 \mathrm{~mol} \%$ 2,2'-bis(trimethylene carbonate-5-yl)-butylether (BTB) was carried out in the conditions of hydrolysis and enzymes in vitro and subcutaneous implantation in vivo. The results showed that the cross-linked PTMC networks exhibited much faster degradation in enzymatic conditions in vitro and in vivo versus in a hydrolysis case due to the catalyst effect of enzymes; the weight loss and physical properties of the degraded networks were dependent on the BTB amount. The morphology observation in lipase and in vivo illustrated that enzymes played an important role in the surface erosion of cross-linked PTMC. The hydrolytic degradation rate of the cross-linked P(TMC-co-CL) networks increased with increasing $\varepsilon$-caprolactone (CL) content in composition due to the preferential cleavage of ester bonds. Cross-linking is an effective strategy to lower the degradation rate and enhance the form-stability of PTMC-based materials.
\end{abstract}

Keywords: cross-linked networks; poly(trimethylene carbonate); in vitro degradation; in vivo degradation; form-stability

\section{Introduction}

Biodegradable polymers have been extensively investigated for biomedical and pharmaceutical applications including implanted medical devices [1-6], drug delivery systems [7-13], nerve guides [14-16] and temporary three-dimensional (3D) scaffolds in tissue engineering [17-22]. Poly(trimethylene carbonate) (PTMC) is one of the most important biodegradable polymers due to its favorable characteristics, such as excellent degradability and biocompatibility [23-25]. In previous work, it has been demonstrated that PTMC was hardly degraded in aqueous solutions $[23,26]$, whereas its degradation was rapid in vivo via surface erosion mechanism [23,25]. The degradation products of PTMC were not acidic, which was much better than polyesters at avoiding the inflammation [27-30] led by acidic degradation products. PTMC was degraded when incubated in lipase solutions (from Thermomyces Lanuginosus) [23]. Once degraded, PTMC loses it shape due to the lack of structural stability [31], which is undesirable to limit the applications in medical implants. Hence, the enhancement of form-stability was considered as one of effective strategies to improve the in vivo usability of PTMC.

PTMC-based biodegradable cross-linked networks (BCNs) have been reported to enhance the mechanical and degradation properties of PTMC. The $\gamma$ irradiation cross-linked PTMC network [32] 
showed that the cross-linking degree of networks increased with increasing the radiation dose and the mechanical properties could be strengthened. Erhan Bat et al. [33,34] cross-linked melt pressed (co)polymer films of trimethylene carbonate (TMC) and CL via $\gamma$ irradiation in vacuum and investigated the in vitro and in vivo degradation of the networks. The results revealed that the degradation of networks was in accordance with a surface erosion mechanism, and the erosion rates could be controlled by the TMC/CL ratio and the irradiation dose. Furthermore, histological evaluation indicated that the networks initiated a mild tissue response when implanted intramuscularly in rats [34]. Similar to the gamma irradiated PTMC networks, BCNs based on UV-photocrosslinked star copolymers of TMC and CL also have been demonstrated to be well tolerated by the host tissue [35]. Therefore, PTMC-based BCNs possessed excellent tensile strength, flexibility and controllable degradation rates, and have potential applications in a broad range of medical fields [36-40].

Recently, we fabricated PTMC-based BCNs using a new reaction methodology of cross-linking agent other than $\gamma$ irradiation to avoid the chain scission during the cross-linking [41]. In addition, 2,2'-bis(trimethylene carbonate-5-yl)-butylether (BTB) synthesized from di(trimethylene propane) and ethyl chloroformate was used as cross-linker in the (co)polymerization of TMC and $\varepsilon$-caprolactone $(\mathrm{CL})$ in the presence of stannous octanoate $\left(\mathrm{Sn}(\mathrm{Oct})_{2}\right)$. The effects of cross-linker amount and CL content on the performance of the resulted elastomers were investigated. A series of structurally stable networks with desired mechanical and thermal properties were received. In this paper, both in vitro and in vivo degradation of the cross-linked PTMC-based BCNs were studied. The in vitro degradation was performed in lipase solutions (from Thermomyces lanuginosus, $\geqslant 100,000 \mathrm{U} / \mathrm{g}$ ) and phosphate buffered saline $(\mathrm{pH}=7.4)$ at $37^{\circ} \mathrm{C}$. The in vivo degradation was carried out in subcutaneous implantation. The form-stability and tissue responses of the implanted networks were studied as well.

\section{Materials and Methods}

\subsection{Materials}

TMC was purchased from Daigang Biomaterial Co., Ltd. (Jinan, Shandong, China), recrystallized twice in ethyl acetate and vacuumed dried at $37^{\circ} \mathrm{C}$ for $24 \mathrm{~h}$ before polymerization. $\varepsilon$-caprolactone $(99 \%)$ was purchased from Sigma-Aldrich (St Louis, MO, USA), freshly distilled over $\mathrm{CaH}_{2}$ under reduced pressure before use. $\mathrm{Sn}(\mathrm{Oct})_{2}(95 \%)$ was purchased from Sigma-Aldrich and used as received. All other solvents and reagents were analytical grades and purified by standard methods.

\subsection{Methods}

${ }^{1} \mathrm{H}-\mathrm{NMR}$ spectra were recorded on a Bruker ARX 300 (Bruker, Zurich, Swiss) using $\mathrm{CDCl}_{3}$ as solvent with tetramethylsilane (TMS) as an internal standard. The molecular weight and distribution $\left(M_{n}\right.$ and PDI) of the sol content were determined by GPC (Waters, Milford, MA, USA) with a Waters Model 1515 isocratic high-performance liquid chromatography (HPLC) pump, a Waters Model 2414 differential refractive index detector and a Waters Styragel HT4 chromatographic column. THF was used as eluent with a flow rate of $1 \mathrm{~mL} / \mathrm{min}$ at $35^{\circ} \mathrm{C}$. The molecular weight and molecular weight distributions were calculated using polystyrene as standard. Glass transition temperature of the networks was determined with a Netzsch DSC 200 F3 (Netzsch, Selb, Germany) equipped with a liquid nitrogen cooling system. The measured temperature range was between -100 and $100{ }^{\circ} \mathrm{C}$ and the heating rate was $10^{\circ} \mathrm{C} / \mathrm{min}$ under nitrogen atmosphere. The thermal stability of the polymers under nitrogen atmosphere was carried out by a Netzsch TGA 209 F3 (Netzsch, Selb, Germany) at a temperature ranging from room temperature to $550{ }^{\circ} \mathrm{C}$ and the heating rate was $10{ }^{\circ} \mathrm{C} / \mathrm{min}$. Tensile testing was performed on the obtained networks measuring approximately $40 \times 3 \times 2 \mathrm{~mm}^{3}$ using an Instron 1121 universal testing machine (Instron, Grove, PA, USA) with a crosshead speed of $50 \mathrm{~mm} / \mathrm{min}$ in accordance with GB/T 1040.1-2006. The tests were done on triplicate samples, and the results were presented as an average for tested samples. The scanning electron microscopy 
(SEM) micrographs were obtained from a XL30ESEM-FEG microscope (FEI-Philips, Eindhoven, The Netherlands). The sample surfaces were sputter coated with Au to avoid charging.

\subsection{Preparation of Network Films}

A mixture of monomers (TMC and/or CL) and BTB (prepared and characterized as described previously [41]) was charged into pre-silanized flat-bottomed ampoules with a diameter of $60 \mathrm{~mm}$ under nitrogen atmosphere, $2 \times 10^{-4}$ mol of $\mathrm{Sn}(\mathrm{Oct})_{2}$ per mole of monomers in anhydrous toluene was added. The toluene was removed by vacuum evaporation. The ampoules were purged three times with dry nitrogen and heat-sealed under vacuum. The ampoules were conditioned in an oil-bath pre-heated at the polymerization temperature and shaken vigorously to mix the mixture homogeneously. The ampoules were put in the oil bath for polymerization. All copolymerizations were carried out at $130 \pm 2{ }^{\circ} \mathrm{C}$ for $24 \mathrm{~h}$. After the reaction, the ampoules were quenched to room temperature, and the films were discharged and easily removed from the ampoules. Figure 1 shows the schematic representation of the formation of the cross-linked P(TMC-co-CL) networks.
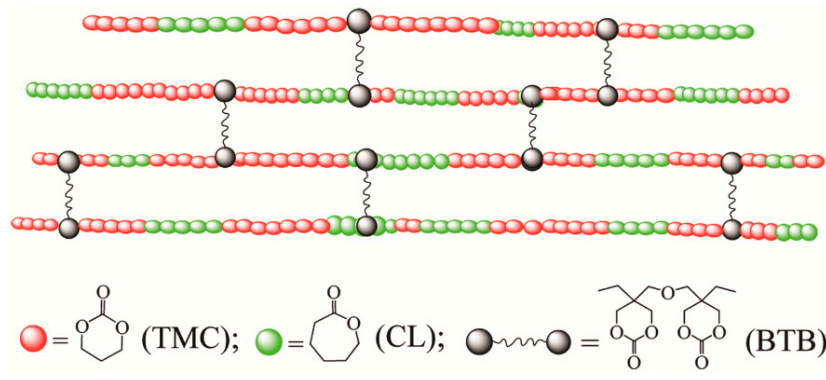

Figure 1. Schematic representation of the formation of the P(TMC-co-CL) networks cross-linked by BTB.

To determine the gel percentage of the network films, a piece of sample was weighed and kept in a sealed flask containing chloroform for 1 week and the solvent was refreshed twice a week to remove the sol fraction completely. The swollen gels were taken out and dried to constant weight at $37^{\circ} \mathrm{C}$ in vacuum. The gel and the sol fractions were calculated according to Equations (1) and (2), respectively:

$$
\begin{gathered}
\text { gel percentage }(\%)=\frac{w_{d}}{w_{i}} \times 100, \\
\text { sol percentage }(\%)=\left(1-\frac{w_{d}}{w_{i}}\right) \times 100,
\end{gathered}
$$

where $w_{\mathrm{d}}$ is the mass of dried swollen samples and $w_{\mathrm{i}}$ is the mass of the specimens before swelling. The measurement for gel and the sol fractions was done in triplicate for each network sample.

\subsection{In Vitro Enzymatic Degradation}

Circular specimens with a diameter of $10 \mathrm{~mm}$ were punched out of the films, weighed and put in lipase solutions (from Thermomyces lanuginosus, $\geqslant 100,000 \mathrm{U} / \mathrm{g}$ ), the media were refreshed twice a week. The degradation experiments were performed in triplicate at $37^{\circ} \mathrm{C}$ with gentle shaking. At regular time intervals, the polymer specimens were taken out from the degradation media, blotted with a tissue and weighed. The specimens were washed with deionized water and then vacuum-dried at $37^{\circ} \mathrm{C}$ till constant weight. The water uptake and mass loss were calculated according to the following equations:

$$
\begin{gathered}
\text { Water uptake }(\%)=\frac{w_{w}-w_{d}}{w_{d}} \times 100, \\
\operatorname{Mass} \operatorname{loss}(\%)=\frac{w_{i}-w_{d}}{w_{\mathrm{i}}} \times 100,
\end{gathered}
$$


where $w_{\mathrm{i}}, w_{\mathrm{w}}$, and $w_{\mathrm{d}}$ represent the initial weight, wet weight and dry weight of the samples, respectively.

\subsection{In Vitro Hydrolytic Degradation}

Strip shaped specimens with dimensions of approximately $40 \times 3 \times 2 \mathrm{~mm}^{3}$ were cut from the films for hydrolytic degradation study. The samples were immersed into vials containing $20 \mathrm{~mL}$ of pH 7.4 phosphate buffered saline (PBS), which was replaced once a week and the vials were placed in an incubator at $37^{\circ} \mathrm{C}$. At time points of 10, 15, 20, 25 and 30 weeks, the samples were removed from PBS and washed with deionized water. After wiping, the specimens were weighed and dried at $37^{\circ} \mathrm{C}$ in vacuum till constant weight. Mass loss and water uptake were then determined.

\subsection{In Vivo Degradation}

Before subcutaneous implantation, strip shaped specimens with dimensions of approximately $40 \times 3 \times 2 \mathrm{~mm}^{3}$ were sterilized by soaking in $75 \%$ ethanol for $3 \mathrm{~h}$, rinsed with deionized water and air-dried in a sterile environment. Animal experiments were performed according to the Regulations of Experimental Animal Administration issued by The people's Government of Liaoning province (Decree No. 143 of 1 October 2002). Adult male Wistar rats with body weight of $200 \mathrm{~g}$ were used. Four specimens of one sample were implanted in the back of one rat for each time point.

After implanted for 2, 4, 810,12 and 14 weeks, the rats were sacrificed and shaved, and the surrounding tissues of implants were excised. Three implants of one polymer in each study point were pulled out from the fibrous tissue capsules gently with tweezers and one with surrounding tissue was used for histological examination. Silastic tubes were used as positive controls.

The explants were fixed in neutral buffered formalin for $24 \mathrm{~h}$. After being rinsed in distilled water and dehydrated in graded alcohol solutions, the explants were embedded in paraffin wax. Histological sections $(5 \mu \mathrm{m})$ were routinely stained with hematoxylin eosin (HE). The histology was independently evaluated by two persons.

\section{Results and Discussion}

\subsection{Synthesis of Cross-Linked PTMC Networks}

To enhance the form-stability and control the degradation rate of PTMC for implant applications, PTMC-based cross-linked networks were prepared using BTB as cross-linker (Table 1). After copolymerization, the products were isolated as transparent solids and insoluble partially in chloroform. To determine the gel and sol fractions, the products were thoroughly washed and extracted with chloroform and there was weak gel left, which was easily broken when being picked up with tweezers due to low gel percentage. The gel percentage of the products was listed in Table 1. Obviously, the TMC content influenced the gel percentage greatly, and higher TMC content resulted in higher gel percentage of the films, similar to the observation in our previous work [41]. This was attributed to the fact that BTB copolymerizes better with TMC because it has a similar reactivity to TMC monomer. Moreover, the gel percentage of the networks increased with increasing the BTB amount in feeding dose. After extraction, the soluble parts were collected by evaporation under reduced pressure and analysis by ${ }^{1} \mathrm{H}-\mathrm{NMR}$. The results showed that there were no proton signals of $\mathrm{BTB}$ in the ${ }^{1} \mathrm{H}-\mathrm{NMR}$ spectrum, which implied the successful incorporation of BTB to the networks. The molecular weight of the sol fractions was also given in Table 1. The sol fractions had higher $M_{\mathrm{n}}$ and narrower PDI than that of sol fractions extracted from the networks cross-linked by gamma irradiation [33]. This indicated that the BTB as cross-linking agent could avoid chain scission during cross-linking. 
Table 1. The characteristics of PTMC based networks ${ }^{\text {a }}$.

\begin{tabular}{|c|c|c|c|c|c|c|c|c|c|c|c|}
\hline \multirow{2}{*}{ No. } & \multicolumn{3}{|c|}{ Monomers (mol) } & \multirow{2}{*}{ Gel percentage ${ }^{b}(\%)$} & \multirow{2}{*}{$M n^{c}(g / m o l)$} & \multirow{2}{*}{$\mathrm{PDI}^{\mathrm{c}}$} & \multirow{2}{*}{$\operatorname{Tg}{ }^{d}\left({ }^{\circ} \mathrm{C}\right)$} & \multirow{2}{*}{$\operatorname{Td}\left({ }^{\circ} \mathrm{C}\right)$} & \multirow{2}{*}{$E^{\mathrm{e}}(\mathrm{MPa})$} & \multirow{2}{*}{$\sigma \mathbf{m}^{\mathrm{f}}(\mathrm{MPa})$} & \multirow{2}{*}{$\varepsilon m \mathrm{~m}(\%)$} \\
\hline & TMC & CL & ВТВ & & & & & & & & \\
\hline N100 & 100 & 0 & 0 & $\mathrm{n} / \mathrm{a}$ & 274,700 & 1.07 & -16.2 & 254.7 & $3.08 \pm 0.18$ & $3.32 \pm 0.23$ & $3570 \pm 514$ \\
\hline N100-1 & 100 & 0 & 0.01 & $19 \pm 2$ & 265,200 & 1.11 & -14.7 & 286.8 & $3.18 \pm 0.16$ & $4.48 \pm 0.59$ & $2150 \pm 212$ \\
\hline N100-2 & 100 & 0 & 0.02 & $31 \pm 2$ & 288,400 & 1.06 & -13.8 & 291.7 & $3.98 \pm 0.20$ & $6.69 \pm 0.71$ & $1350 \pm 208$ \\
\hline N75-1 & 75 & 25 & 0.01 & $11 \pm 2$ & 260,100 & 1.14 & -31.4 & 296.8 & $2.69 \pm 0.14$ & $3.43 \pm 0.12$ & $3350 \pm 173$ \\
\hline N50-1 & 50 & 50 & 0.01 & $8 \pm 3$ & 240,500 & 1.21 & -44.1 & 306.3 & $1.83 \pm 0.23$ & $1.30 \pm 0.08$ & $163 \pm 10$ \\
\hline
\end{tabular}

a Values are expressed as mean. Standard deviation $(n=3){ }^{\mathrm{b}}$ Values of gel fraction determined by using chloroform at room temperature; ${ }^{\mathrm{c}}$ Values of sol fraction determined by GPC at

$35^{\circ} \mathrm{C}$ using THF as the eluent; ${ }^{\mathrm{d}}$ measured from the second heating cycle; ${ }^{\mathrm{e}} E=$ elastic modulus; ${ }^{\mathrm{f}} \sigma \mathrm{m}=$ tensile stress; ${ }^{\mathrm{g}} \mathrm{\varepsilon m}=$ tensile strain 
The thermal and mechanical properties of the network films were shown in Table 1. The cross-linked $\mathrm{P}$ (TMC-co-CL) networks containing 100, 75 and $50 \mathrm{~mol} \%$ TMC were rubbery under physiological temperature and the Tgs ranged from -16.2 to $-44.1^{\circ} \mathrm{C}$. The Tgs of cross-linked PTMC networks were slightly higher than that of non-crosslinked one due to the restricted motion of chain segments caused by cross-linking. A similar observation was found for the cross-linked P(TMC-co-CL) networks as compared to the linear P(TMC-co-CL) [42]. Furthermore, the Tgs of cross-linked P(TMC-co-CL) networks decreased with increasing $\mathrm{CL}$ content, which was attributed to the low glass transition temperature of PCL (around $-60^{\circ} \mathrm{C}$ ).

The obtained networks were flexible with elastic modulus ranging between 1.83 and $3.98 \mathrm{MPa}$. The elastic modulus and the tensile strengths of the networks increased with the increase of cross-linker amount while decreasing with the increase of CL content. It was due to the higher activity of the BTB, which was preferable to react with TMC monomer, thus resulting in less cross-linking points and low gel percentage in the network when CL content increased. The thermal and mechanical properties indicated that the PTMC-based cross-linked networks were elastic and flexible biomaterials potentially for subcutaneous implants.

\subsection{In Vitro Enzymatic Degradation}

Lipase (from Thermomyces lanuginosus, $\geqslant 100,000 \mathrm{U} / \mathrm{g}$ ) was used as a model enzyme to investigate the enzymatic degradation of the cross-linked PTMC. Figure 2 showed the mass loss of cross-linked N100-1 and non-crosslinked N100 specimens in lipase solutions.

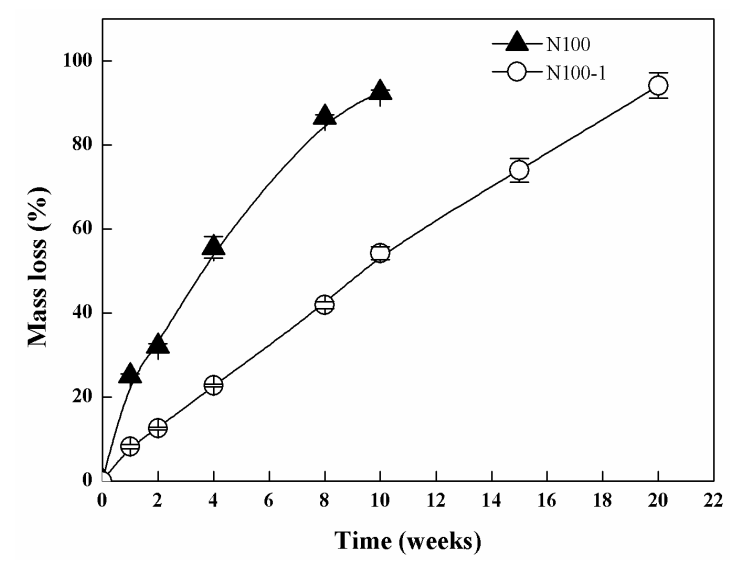

Figure 2. Mass loss of N100 and N100-1 specimens conditioned in lipase solutions at $37^{\circ} \mathrm{C}$ for different time periods.

As expected, N100-1 presented a slower mass loss than N100. After 10 weeks, the mass loss of $\mathrm{N} 100-1$ was $54.23 \% \pm 1.56 \%$ and that of $\mathrm{N} 100$ was $92.44 \% \pm 0.62 \%$, and the N100 sample was almost eroded completely within 10 weeks. This observation showed that the cross-linked PTMC networks were more insensitive and resistant to lipase degradation. Cross-linking showed significant influence on the degradation behavior and could greatly lower the degradation rate of PTMC.

The macroscopic morphologies of the cross-linked PTMC network specimens degraded in enzymatic conditions were observed. As displayed in Figure 3A, the shape of N100 specimens was not circular anymore, but highly irregular after being degraded in lipase solutions for eight weeks. N100-1 exhibited better form-stability during incubating in the lipase solution at $37^{\circ} \mathrm{C}$ for 15 weeks. The shape was not changed appreciably, and the diameter remained more or less constant (Figure 3B), while the thickness of the discs decreased with degradation time (Figure 4). At 20 weeks, the specimens of N100-1 were thin with serrate margins and visible pores on the surface. The change in the appearance of the N100 and N100-1 revealed that the cross-linked PTMC networks had a better form-stability than the non-crosslinked ones. 

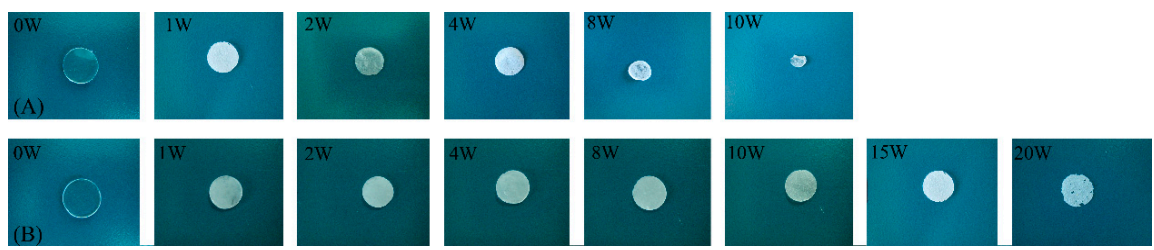

Figure 3. Shape of N100 (A) and N100-1 specimens (B) at different times of enzymatic degradation in lipase solutions. The initial diameter of the specimens was $10 \mathrm{~mm}$.

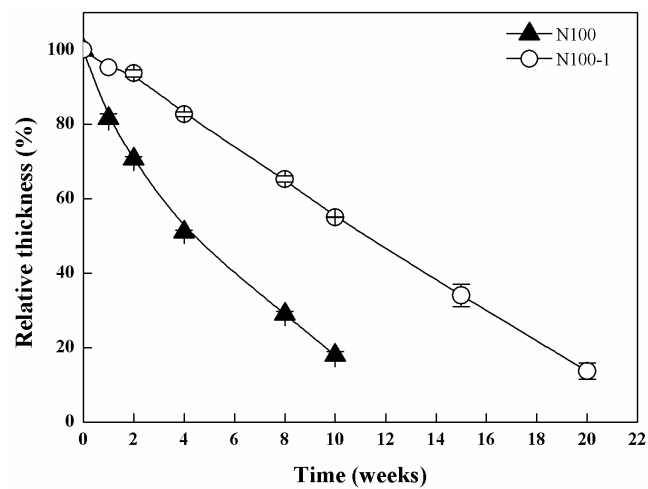

Figure 4. Relative thickness of N100 and N100-1 conditioned in lipase solutions at $37{ }^{\circ} \mathrm{C}$ for different times.

SEM measurements were performed to examine the changes in surface morphology of the PTMC-based networks before and after degradation. The original samples of the cross-linked PTMC networks (N100-1) exhibited a smooth surface before enzymatic degradation. However, a highly porous structure was detected after 2, 10 and 15 weeks of degradation, and the size and deepness of the pits observed on the surface increased with the incubation time, as illustrated in Figure 5. The results were similar to the findings previously reported for PTMC [43], demonstrating that the cross-linked PTMC was degraded in lipase solutions via a surface erosion process.

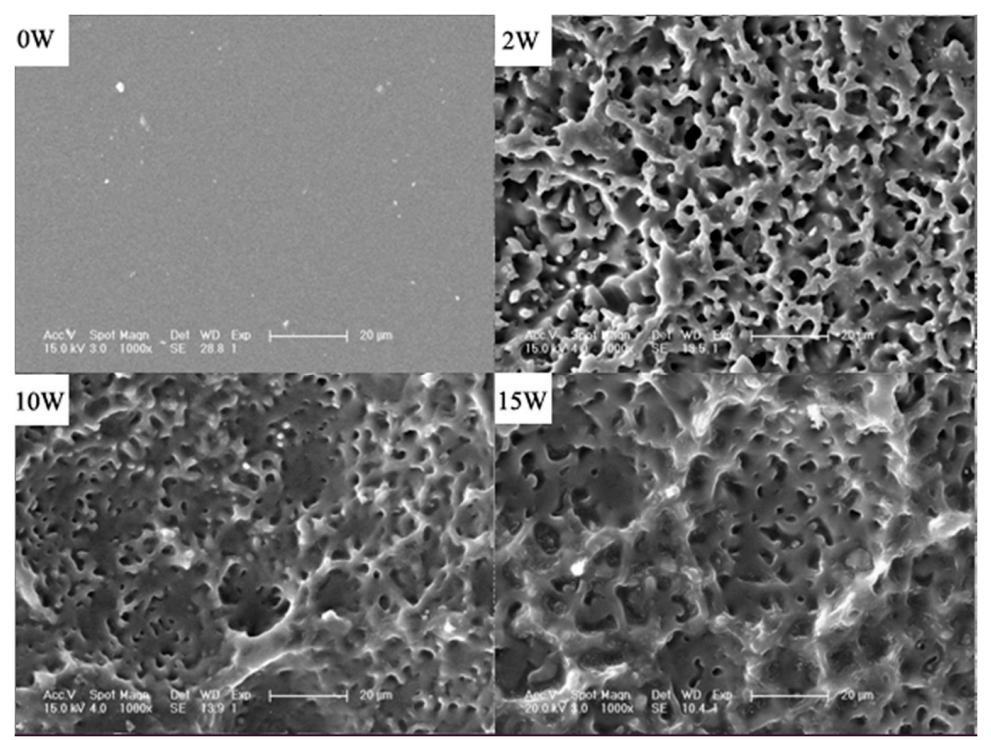

Figure 5. SEM micrographs of N100-1 before and after 2, 10 and 15 week enzymatic degradation. The scale bar was $20 \mu \mathrm{m}$. 
Figure 6 illustrated the water uptake curves during enzymatic degradation of the networks. N100 presented a gradual increase in water uptake; the water uptake was $15.47 \% \pm 1.86 \%$ after 10 weeks and that of N100-1 was approximately $5.68 \% \pm 0.11 \%$ after 20 weeks. The lower water uptake of cross-linked PTMC was in virtue of the fact that the cross-linked PTMC had a significantly slower degradation rate with less porous pits and holes on the surface (Figure 2), where the diffusivity of solvent molecules was less.

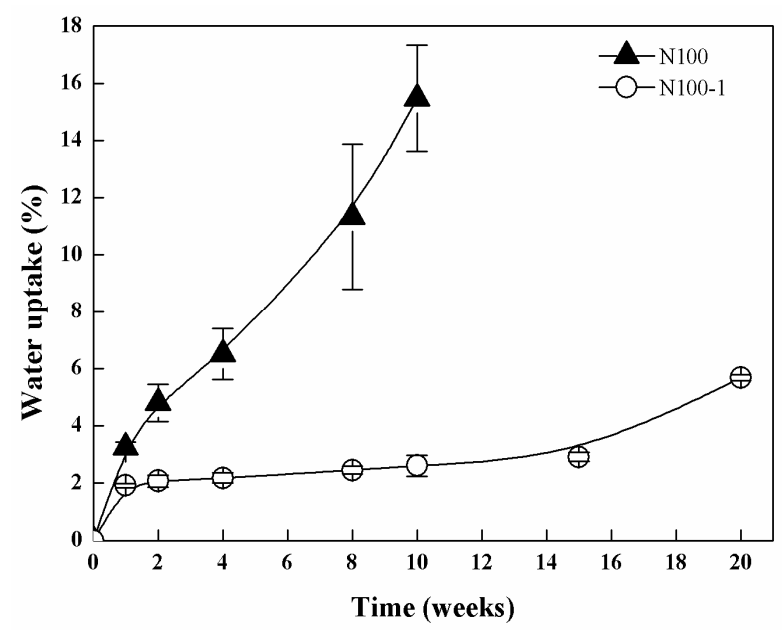

Figure 6. Water uptake of N100 and N100-1 specimens conditioned in lipase solutions at $37^{\circ} \mathrm{C}$ for different time periods.

The thermal properties of the cross-linked PTMC network (N100-1) in vitro enzymatic degradation were evaluated by DSC and TGA, and the representative curves were shown in Figure 7.
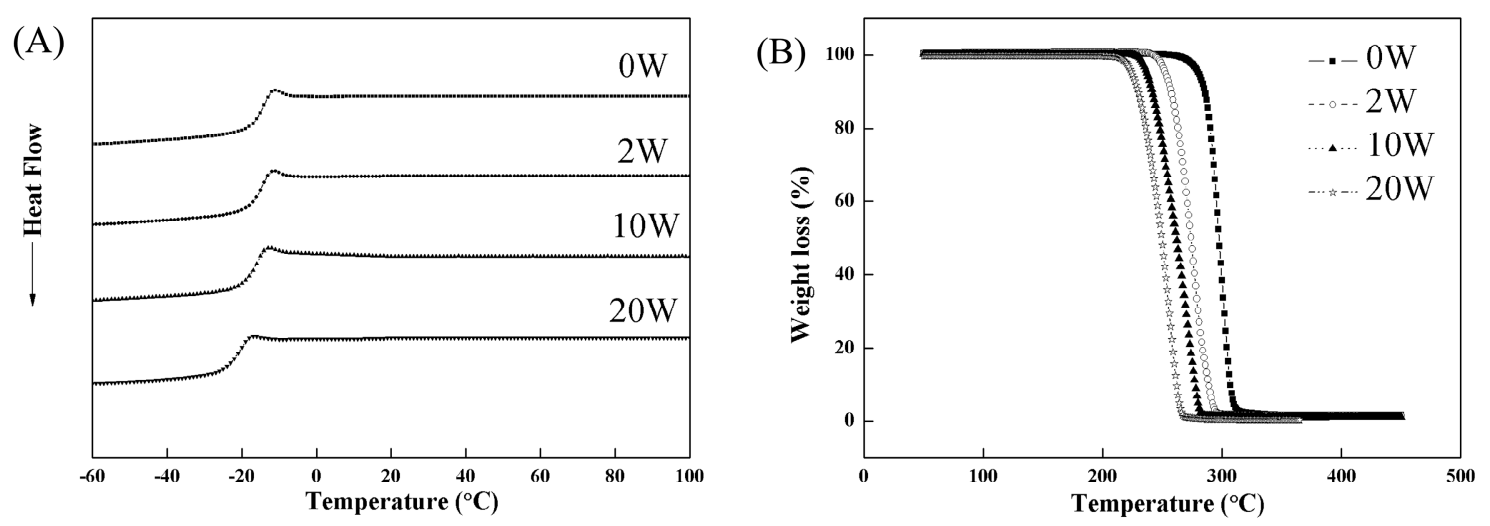

Figure 7. DSC (A) and TGA (B) curves of N100-1 conditioned in lipase solutions at $37{ }^{\circ} \mathrm{C}$ for different times.

Figure 8 shows the changes in $T \mathrm{~g}$ and $\mathrm{Td}$ of N100-1 during in vitro enzymatic degradation. Both the $T \mathrm{~g}$ and $\mathrm{Td}$ decreased with increasing degradation time, and they were -21.2 and $234.0^{\circ} \mathrm{C}$ after degradation for 20 weeks. This result indicated that the enzymatic degradation could destruct the structure and decrease the thermal stability of the cross-linked PTMC significantly. 


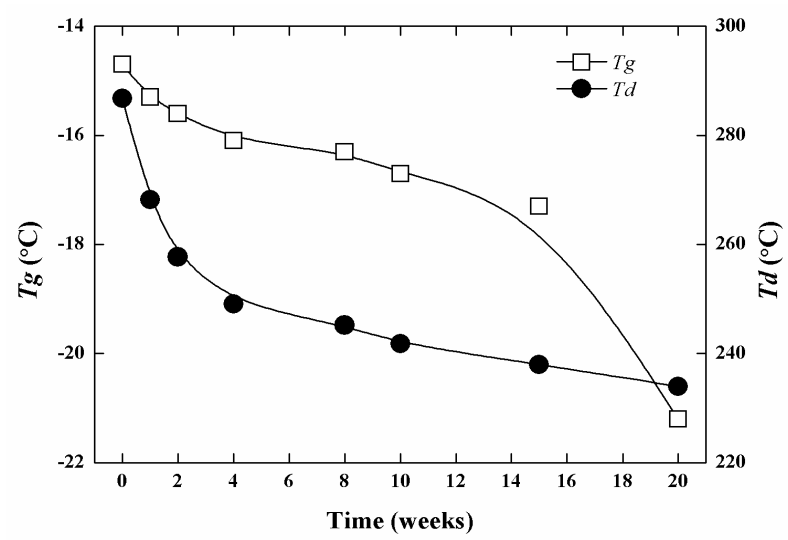

Figure 8. Change in thermal properties of N100-1 during in vitro enzymatic degradation in lipase solutions at $37^{\circ} \mathrm{C}$.

The samples conditioned in the enzymolysis cases were too short and weak to be clamped for tensile test, hence their mechanical properties were not be measured.

\subsection{In Vitro Hydrolytic Degradation}

The hydrolytic degradation of the PTMC-based networks was performed in pH 7.4 PBS at $37^{\circ} \mathrm{C}$. The cross-linked PTMC network N100-1 degraded extremely slowly due to the hydrophobic characteristics of PTMC [26], and the mass loss was only $1.71 \% \pm 0.26 \%$ after 30 weeks of degradation. In contrast, the cross-linked $\mathrm{P}(\mathrm{TMC}-\mathrm{co}-\mathrm{CL})$ networks were hydrolytically degradable and the mass loss rapidly increased to $5.90 \% \pm 0.32 \%$ for N75-1 and $13.01 \% \pm 1.45 \%$ for N50-1 at week 30 , as shown in Figure 9. Apparently, the cross-linked P(TMC-co-CL) networks degraded much faster than the cross-linked PTMC networks, the degradation rates of copolymer networks increased with the increase of the CL content due to the hydrolysis of ester bonds [27]. Furthermore, the mass loss of cross-linked PTMC networks in hydrolytic degradation was less than that in enzymatic degradation, implying the significant contribution of enzyme to the degradation of cross-linked PTMC networks.

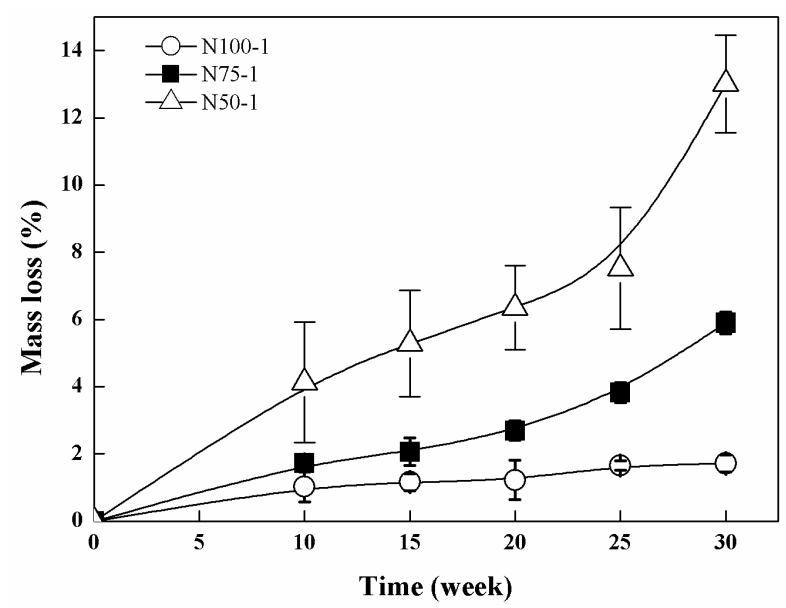

Figure 9. Mass loss of the cross-linked P(TMC-co-CL) networks during hydrolytic degradation.

The cross-linked P(TMC-co-CL) networks exhibited wonderful form-stability and no significant deformation was observed during the hydrolytic degradation process with the exception of N50-1 that became bended at 12 weeks (Figure 10). The slight deformation of N50-1 might be attributed to the lowest gel percentages and the fastest degradation rat. In our previous works, we reported that the non-crosslinked P(TMC-co-CL) copolymers presented poor form-stability and unexpectedly began 
changing their shape from a cylinder to an oblate sphere after 10 weeks in vitro hydrolytic degradation. The results indicated that cross-linking is an effective strategy to enhance the form-stability of the linear P(TMC-co-CL) copolymers.
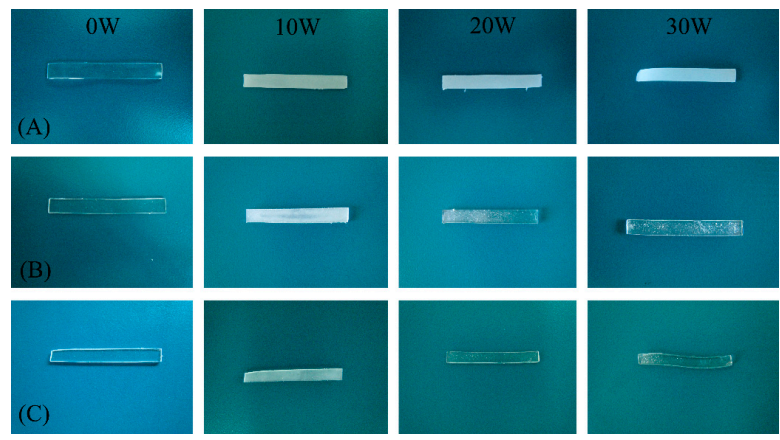

Figure 10. Macroscopic observation of the cross-linked $\mathrm{P}(\mathrm{TMC}-\mathrm{co}-\mathrm{CL})$ networks during hydrolytic degradation: (A) N100-1; (B) N75-1; and (C) N50-1.

Similar to the enzymolysis cases, the surface of the cross-linked P(TMC-co-CL) networks before in vitro hydrolytic degradation was smooth, and it became rough and a number of pits were also visible on the surface after 10 weeks of degradation. For N100-1, the pits grew in size with degradation time (Figure 11A), indicating the further degradation. However, the pits size observed on the surface of N75-1 and N50-1 seemed to be smaller with degradation, and the surface became relative smooth (Figure 11B,C), although the mass loss increased significantly as shown in Figure 9. It was attributed to the viscous flow caused by the plasticizing effect of the low molecular weight degradation products leaching out of the degrading samples, which led to the structure collapse and formed the smooth surface.

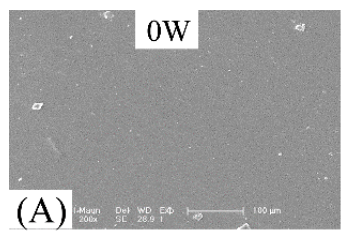

(A)
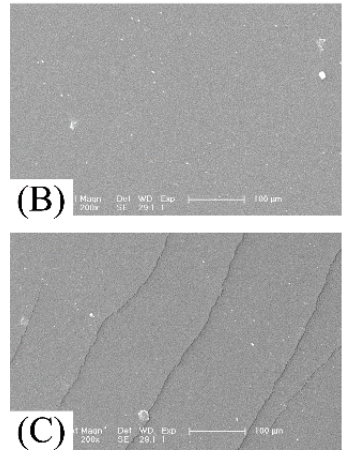
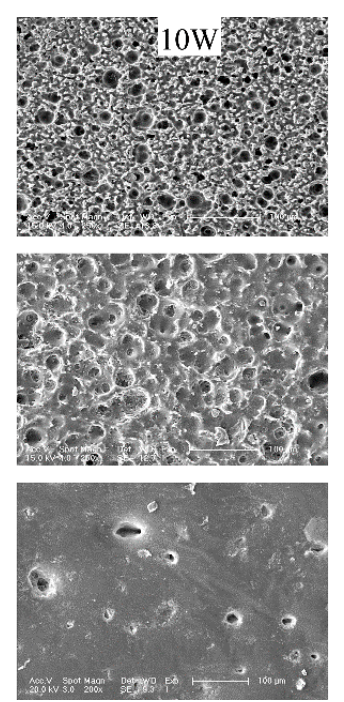
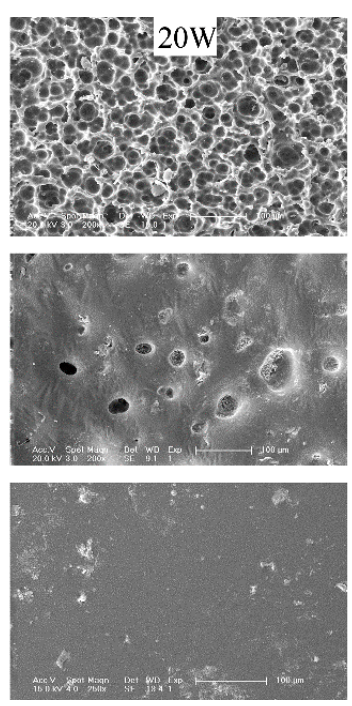
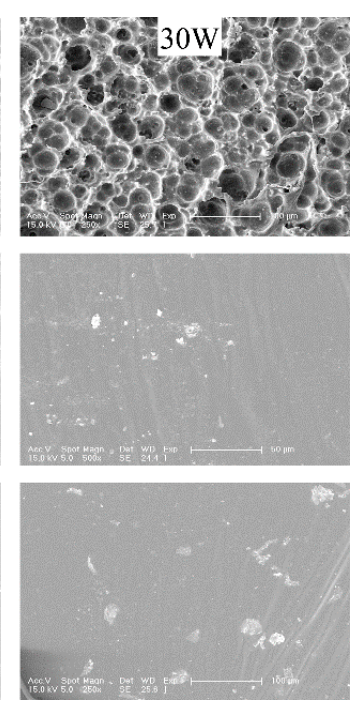

Figure 11. SEM micrographs of the cross-linked $\mathrm{P}(\mathrm{TMC}-\mathrm{Co}-\mathrm{CL})$ networks before and after the in vitro hydrolytic degradation: (A) N100-1; (B) N75-1; (C) N50-1. The scale bar was $100 \mu \mathrm{m}$ for all images with exception of $50 \mu \mathrm{m}$ for N75-1 at week 30 .

Figure 12 presents the water uptake profiles of the cross-linked P(TMC-co-CL) networks during hydrolytic degradation. N100-1 was very hydrophobic and its water uptake was $2.11 \% \pm 0.52 \%$ after 30 weeks. N75-1 and N50-1 presented slightly higher water uptakes with $2.93 \% \pm 0.45 \%$ and $3.65 \% \pm 0.43 \%$, respectively. The higher water uptake was due to the degradation of ester bonds in the cross-linked copolymers. 


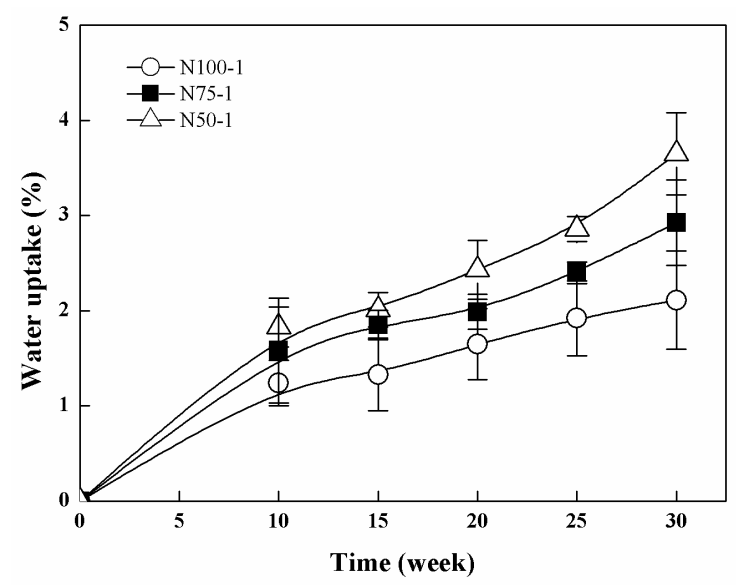

Figure 12. Water uptake s of the cross-linked P(TMC-co-CL) networks during hydrolytic degradation.

The Tgs of the cross-linked P(TMC-co-CL) networks were not significantly changed (Figure 13A) while the Td decreased gradually (Figure 13B) under hydrolytic conditions in vitro, especially for the networks containing $50 \mathrm{~mol} \% \mathrm{CL}$ (N50-1), which had a decrease of $17.60 \%$ in Td after 30 weeks, it was due to more server destruction of the reticulate structure as indicated by the higher mass loss (Figure 9). Furthermore, the decrease in $M_{\mathrm{n}}$ and loss of CL content in composition of the sol fraction during the degradation process would also lower the value of $T d$, as reported in our previous works that had researched the degradation behavior of the linear P(TMC-co-CL) [42]. Obviously, there was a significant increase in Td of the cross-linked PTMC N100-1 after 20 weeks in PBS solutions (Figure 13B), which was caused by the first degradation of sol fractions. It resulted in the relative increase of gel contents and led to the increase of the thermal stability of the networks.
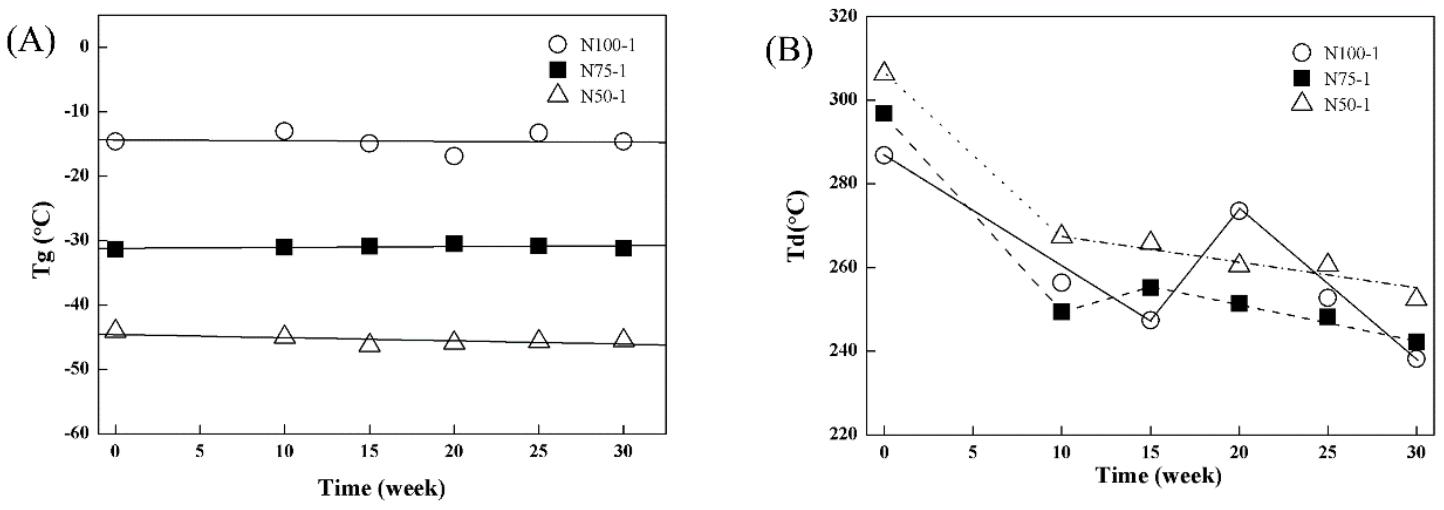

Figure 13. Change in thermal properties of the cross-linked $\mathrm{P}(\mathrm{TMC}-\mathrm{co}-\mathrm{CL})$ networks during in vitro hydrolytic degradation in PBS at $37^{\circ} \mathrm{C}$ : (A) Tg and (B) Td.

The changes in mechanical properties (Young's modulus, E; tensile stress, $\sigma$; and tensile strain, $\varepsilon$ ) of the cross-linked P(TMC-co-CL) networks in vitro hydrolytic degradation were given in Figure 14 . The results were normalized with respect to their initial values $\left(E_{0}, \sigma_{0}\right.$ and $\left.\varepsilon_{0}\right)$.

As seen in Figure 14, there was a clear tendency that all the Young's modulus, tensile stress and tensile strain values of the cross-linked P(TMC-co-CL) networks decreased during the in vitro hydrolytic degradation. The addition of CL content in the copolymers resulted in significant decrease of mechanical properties of the cross-linked copolymer networks. For example, for the cross-linked copolymers, N50-1 contained $50 \mathrm{~mol} \% \mathrm{CL}$, the modulus and tensile stress decreased to $16.4 \%$ and $8.1 \%$ of the initial values after 50 weeks, while the corresponding parameters of cross-linked PTMC N100-1 were $59.0 \%$ and $62.0 \%$ of the initial values. The tensile strain of the cross-linked polymers 
was shown in Figure 14C, and the trend was similar to that of modulus and tensile stress during the hydrolytic degradation.
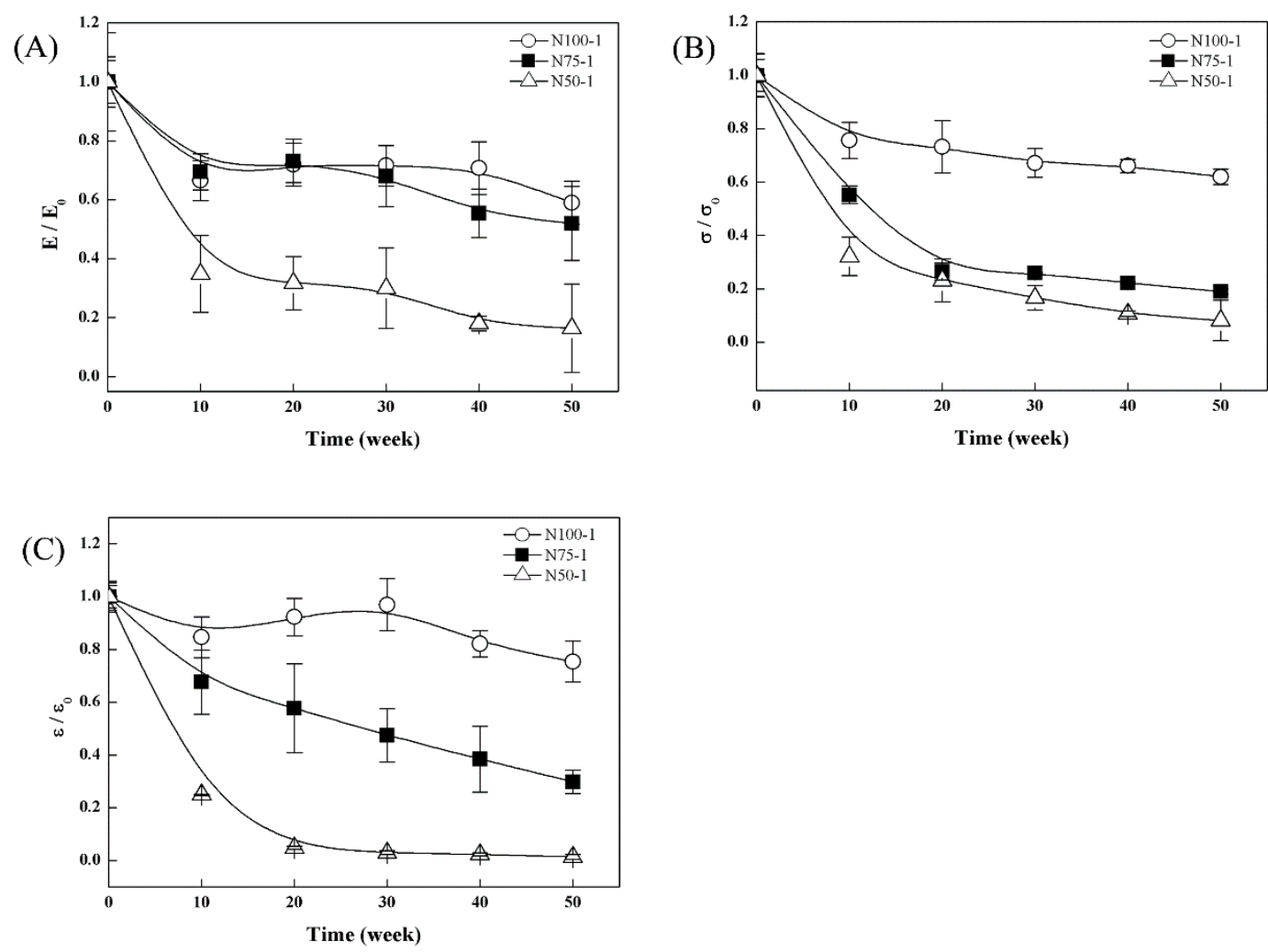

Figure 14. Change in physical properties of the cross-linked $\mathrm{P}(\mathrm{TMC}-\mathrm{co}-\mathrm{CL})$ networks during in vitro degradation in pH 7.4 PBS: (A) Young's modulus (B) tensile stress and (C) tensile strain.

The significant loss in the mechanical properties of the cross-linked copolymer networks was attributed to the higher mass loss caused by the instability of ester bonds in hydrolysis conditions. This result coincided with the hydrolytic degradation results already shown in Figure 9, indicating that the loss in mechanical properties of the cross-linked polymers was directly proportional to the mass loss.

\subsection{In Vivo Degradation}

The implants of all the cross-linked PTMC networks were subcutaneously implanted in the back of rats. The mass loss, thermal properties and mechanical properties of the implants as well as the histology at the sites of implantation were monitored and evaluated.

The mass loss of the cross-linked PTMC networks in vivo was presented in Figure 15. The specimens of N100-1 were completely degraded after 10 weeks, while the N100-2 disappeared at week 14, indicating that the degradation rate decreased with increasing the cross-linker amount in the composition of the networks. It has been reported that high molecular weight PTMC degraded fast in vivo [24,25]; for instance, PTMC discs with molecular weight of $3.16 \times 10^{5} \mathrm{~g} / \mathrm{mol}$ subcutaneously implanted in the back of rats presented a weight loss of $96 \%$ in three weeks. Therefore, N100-1 and N100-2 exhibited a slower degradation rate as compared to the non-crosslinked PTMC mentioned above. The results indicated that cross-linking could lower and tailor the degradation rate of PTMC via the adjustment of cross-linking density. 


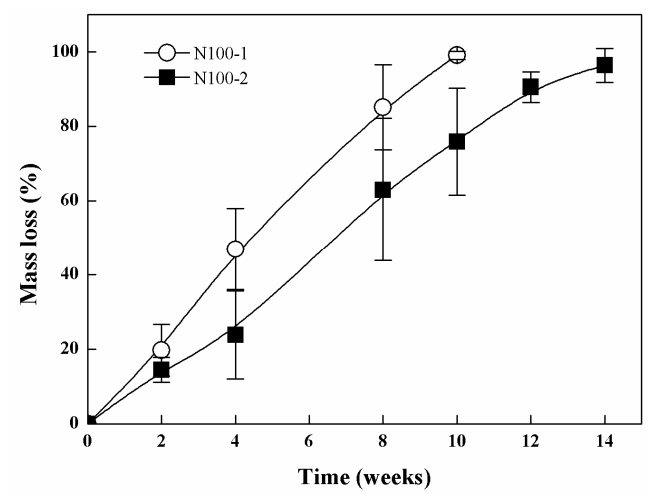

Figure 15. Mass loss of N100-1 and N100-2 at different implantation times in the back of rats.

The shape of the explants was not changed obviously, while the thickness decreased and the surface became rougher (The figures were not given), indicating that the degradation of the cross-linked PTMC in vivo proceeded via surface erosion mechanism. The surface morphology of the explants was observed by SEM as shown in Figure 16, and the surface was smooth without any cracking or pitting before implanting, while the surface of implants was eroded to a highly porous texture and numerous pits were visible after two weeks of implantation. With further degradation, the size and deepness of the pits were greater at eight weeks. Furthermore, the pit size observed on the surface of N100-2 was smaller versus that of N100-1 at each same time point. It further confirmed that the degradation rate of the cross-linked PTMC could be tailored by the cross-linking density: the higher the cross-linking density, the lower the degradation rater. The surface structure of cross-linked PTMC was very similar to that of PTMC films eroded in vivo $[43,44]$. It was likely that the degradation mechanism of these networks was surface enzymatic erosion. The rapid surface erosion of the cross-linked PTMC networks in vivo as well as being stable under hydrolytic conditions suggested that enzymes in body fluid played an important role in the degradation process. However, it is not clear yet which enzyme is dominant for the in vivo degradation of cross-lined PTMC. Meanwhile, body response, such as the accumulation of macrophages, may accelerate degradation [45].

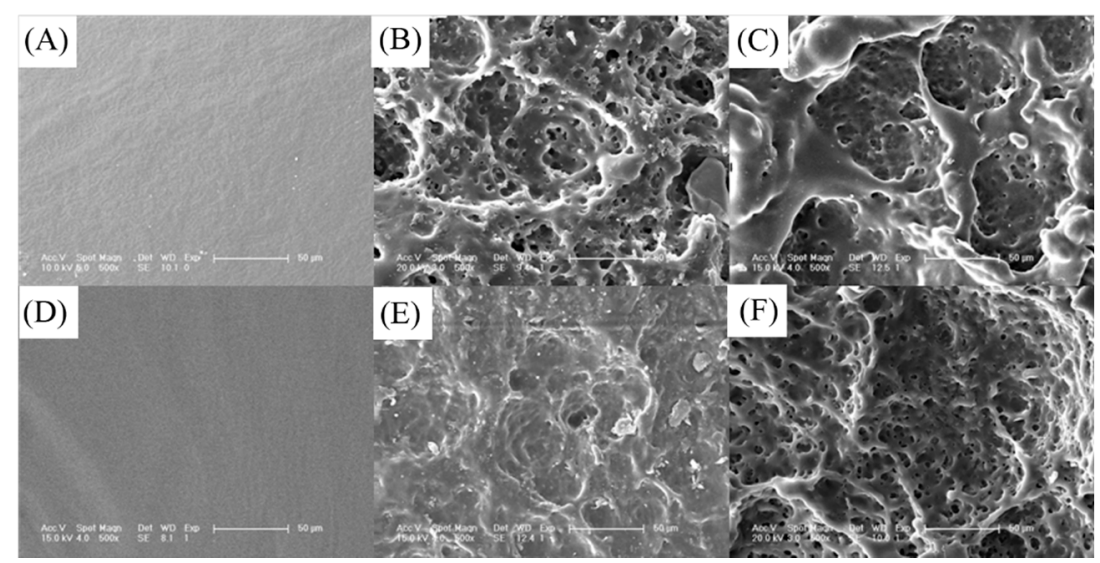

Figure 16. SEM micrographs of the surface of N100-1 (A-C) and N100-2 (D-F) after 0 (A,D); 2 (B,E) and 8 weeks $(\mathbf{C}, \mathbf{F})$ implanted in the back of rats. The scale bar was $50 \mu \mathrm{m}$.

The thermal properties of the cross-linked PTMC degraded in vivo were presented in Figure 17. The thermal properties decreased as the degradation time increased, similar to that in vitro enzymatic degradation. It was quite evident that N100-2 had higher thermal stability than N100-1, which was attributed to the more stable structure caused by cross-linking when the amount of cross-linker increased. 
(A)

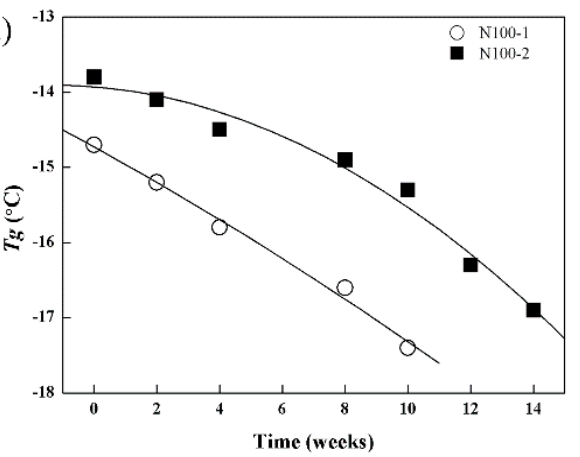

(B)

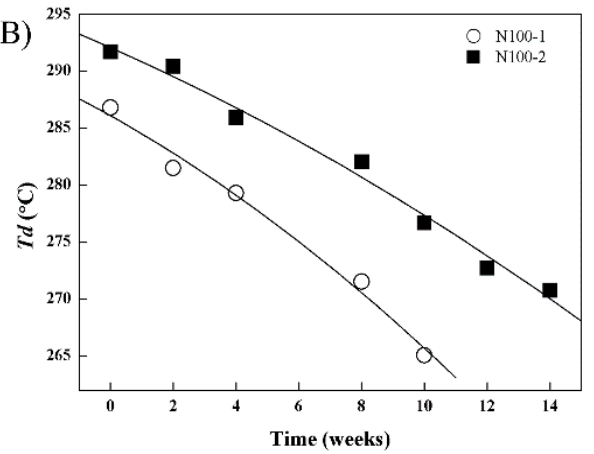

Figure 17. Change in thermal properties of N100-1 and N100-2 networks at different implantation times in the back of rats: (A) $\mathrm{Tg}$ and (B) $\mathrm{Td}$.

Figure 18 shows the changes in mechanical properties of the cross-linked PTMC networks after implantation in vivo. Interestingly, the modulus of cross-linked PTMC N100-1 and N100-2 increased up to $103 \%$ and $118 \%$ of initial modulus in the first four weeks, and they then sharply decreased (Figure 18A). The tensile strength of cross-linked PTMC networks was shown in Figure 18B, and the trend was identical to that of modulus during implantation time. The increase in modulus and tensile strength was attributed to the anti-plasticization effect of hydrogen-bonded bridges established by water molecules penetrated in the inter-chain spaces of cross-linked polymers, once the explants were exposed to water for a short period, and the similar result was reported by other groups [26,46-48]. Different from the changes in modulus and tensile strength with degradation time, the networks underwent a marked decrease in tensile strain. N100-1 samples retained only $42.4 \%$ of their initial values, while N100-2 experienced a lower alteration of decrease to $65.8 \%$ of the initial value for 12 weeks in vivo degradation (Figure 18C). The samples of N100-1 were too weak to be clamped for tensile test and their mechanical properties could not be measured after degraded for 10 weeks. The same phenomena were found to N100-2 samples after 14 weeks degradation.
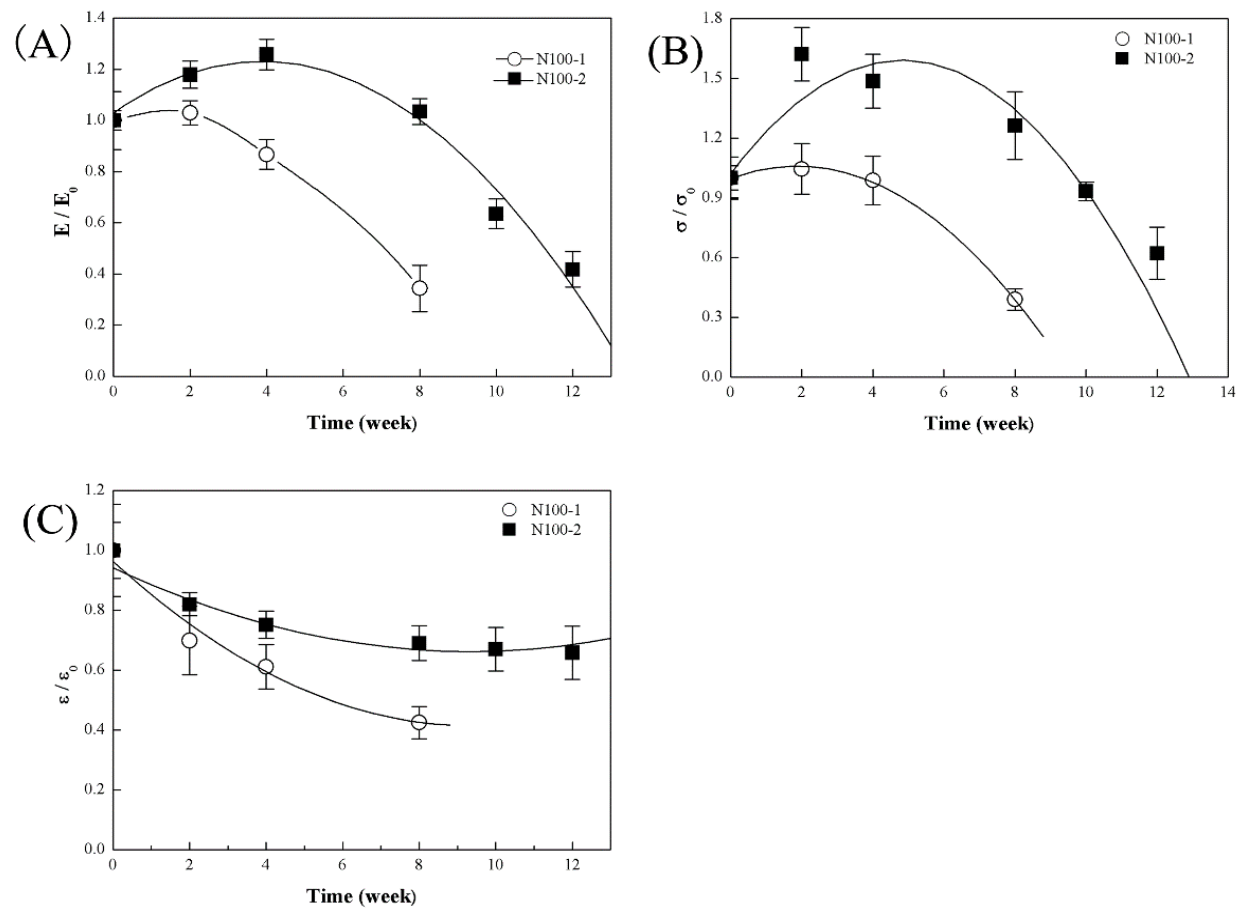

Figure 18. The changes in the mechanical properties of N100-1 and N100-2 networks during in vivo degradation: (A) Young's modulus (B) tensile stress and (C) tensile strain. 
To investigate the influence of degradation on the nature and extent of inflammatory and foreign body reactions, the cross-linked PTMC networks (N100-1 and N100-2) with a different cross-linker amount were implanted. As shown in Figure 19, at week 2, there was a minor inflammatory response at the site of implantation for both N100-1 and N100-2, the signs of formation of fibrous capsule and induction of vascularization were observed around the implants. Cells in the capsule were mainly fibroblasts and fibrocyte with a few multinucleated neutrophils and foreign-body giant cells, and the amount of cells was relatively higher than that around the silastic tube. However, no significant difference in the number of cells was found between the two samples.

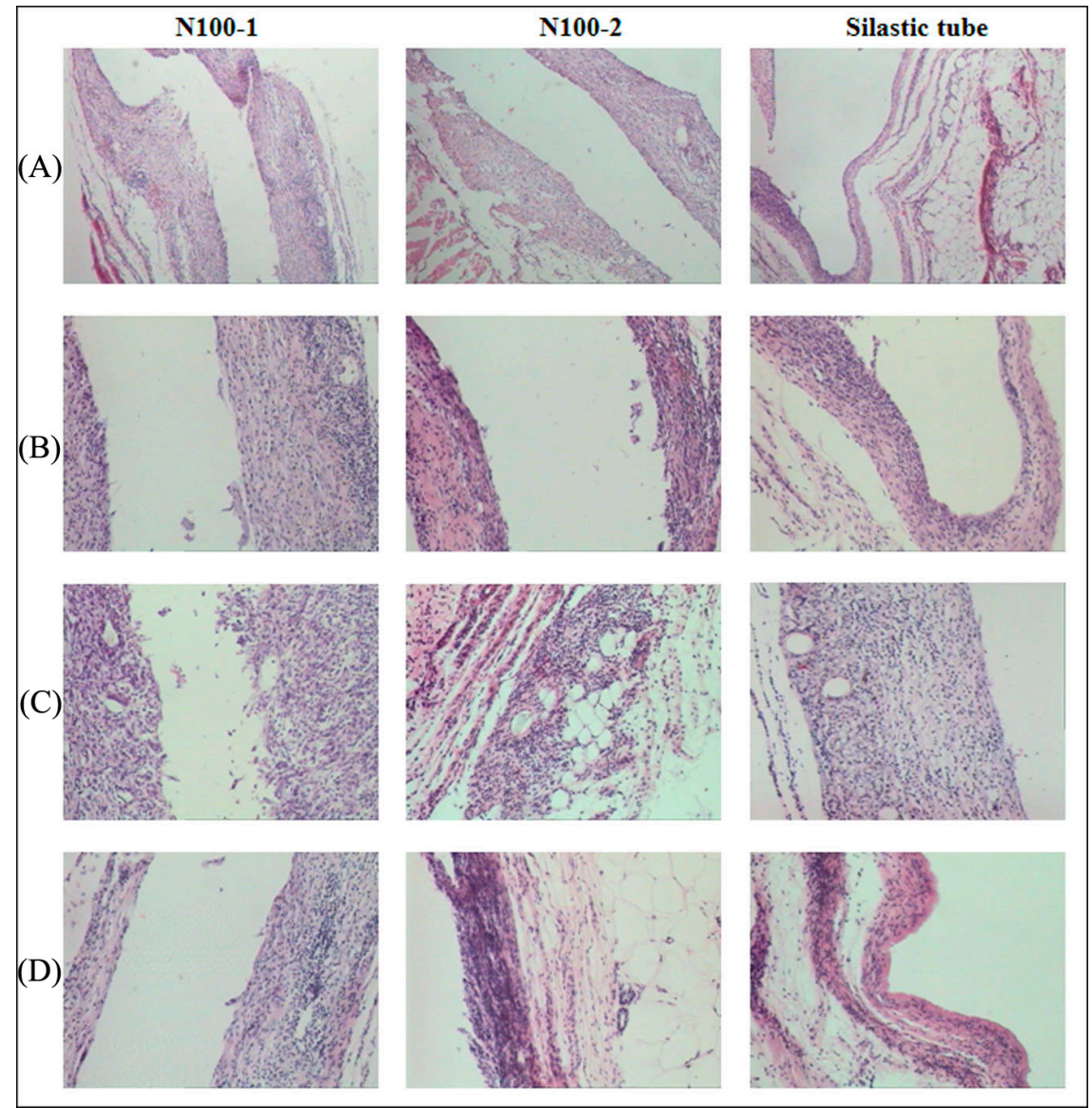

Figure 19. Histological sections of the tissue surrounding the implant at different stages of in vivo degradation: (A) 2 weeks at $40 \times$ magnification; (B) 2 weeks at $100 \times$ magnification; (C) 4 weeks at $100 \times$ magnification and (D) 12 weeks at $100 \times$ magnification.

The thickness of the capsule and the cellular content at the site of implantation increased slightly at week 4 for both elastomeric implants. After 12 weeks post implantation, these fibrous capsules composed of fibroblasts and fibrous tissue appeared to become thinner in a manner similar to other implanted biodegradable polymers [49-51], and the cellular content decreased for all the implants.

At the 4th week of implantation, some small fragments from the implanted networks were found on the tissue-implant interface, which was likely due to the erosion of the implants via phagocytosis, these polymeric fragments were absorbed and disappeared gradually with the prolonged degradation time, avoiding the removal of the degradation products from the site of implantation.

\section{Conclusions}

The degradation of cross-linked PTMC-based networks was investigated both in vitro and in vivo. The degradation rate of cross-linked PTMC networks was slower than that of the linear ones, indicating 
the enhanced resistance to degradation of PTMC via cross-linking with the adjustment of cross-linking density. With the comparison of an in vitro hydrolysis case, the faster degradation rate in lipase or in vivo was attributed to the essential role of enzymes in the erosion of cross-linked PTMC networks. Furthermore, surface morphology observation of the degradation samples demonstrated that the degradation was the surface erosion process. The cross-linked PTMC networks degraded extremely slowly in PBS, while the cross-linked P(TMC-co-CL) degraded dependent on the compositions. The higher the CL content, the faster the degradation. The cross-linked PTMC-based networks maintained better form-stability versus the non-crosslinked ones and were the promising candidates for potential clinical application in subcutaneous implants.

Acknowledgments: This research work was supported by the National Science Foundation of China (NSFC, No. 51133004, 81361140343, 51503093), the National Science Foundation for Excellent Young Scholars (No. 51222304), the Department of Science and Technology of Sichuan Province (2013FZ0003), the Science and Technology Department of Liaoning Province (2015001007, 201501116), and the Science and Technology Bureau of Shenyang City (F16-205-1-37).

Author Contributions: Liqun Yang and Jianxin Li designed the experiments; Liqun Yang and Miao Li performed the experiments; Liqun Yang contributed to the writing of the manuscript; and Zhongwei Gu contributed scientific content related to the PTMC-based networks and revised the manuscript.

Conflicts of Interest: The authors declare no conflict of interest.

\section{References}

1. Mehdikhani-Nahrkhalaji, M.; Fathi, M.H.; Mortazavi, V.; Mousavi, S.B.; Hashemi-Beni, B.; Razavi, S.M. Novel nanocomposite coating for dental implant applications in vitro and in vivo evaluation. J. Mater. Sci. Mater. Med. 2012, 23, 485-495. [CrossRef] [PubMed]

2. Yang, L.Q.; Yang, D.; Guan, Y.M.; Li, J.X.; Li, M. Random copolymers based on trimethylene carbonate and E-caprolactone for implant applications: Synthesis and properties. J. Appl. Polym. Sci. 2012, 124, 3714-3720. [CrossRef]

3. Böstman, O.; Pihlajamäki, H. Clinical biocompatibility of biodegradable orthopaedic implants for internal fixation: A review. Biomaterials 2000, 21, 2615-2621. [CrossRef]

4. Weiler, A.; Hoffmann, R.F.; Stähelin, A.C.; Helling, H.J.; Südkamp, N.P. Biodegradable implants in sports medicine: The biological base. Arthroscop 2000, 16, 305-321. [CrossRef]

5. Witte, F.; Calliess, T.; Windhagen, H. Degradable synthetische implantatmaterialien. Orthopade 2008, 37, 125-130. [CrossRef] [PubMed]

6. Burkhart, S.S. The evolution of clinical applications of biodegradable implants in arthroscopic surgery. Biomaterials 2000, 21, 2631-2634. [CrossRef]

7. Allcock, H.R. Biodegradable Polymers as Drug Delivery Systems; Chasin, M., Langer, R., Eds.; Marcel Dekker: New York, NY, USA, 1990; p. 163.

8. Wang, H.; Dong, J.H.; Qiu, K.Y.; Gu, Z.W. Synthesis of poly(1, 4-dioxan-2-one-co-trimethylene carbonate) for application in drug delivery systems. J. Polym. Sci. A Polym. Chem. 1998, 36, 1301-1307. [CrossRef]

9. Zhang, Z.; Foks, M.A.; Grijpma, D.W.; Feijen, J. PTMC and MPEG-PTMC microparticles for hydrophilic drug delivery. J. Control. Release 2005, 101, 392-394.

10. Zhang, Y.; Zhuo, R.X. Synthesis and drug release behavior of poly(trimethylene carbonate)-poly (ethylene glycol)-poly(trimethylene carbonate) nanoparticles. Biomaterials 2005, 26, 2089-2094. [CrossRef] [PubMed]

11. Gu, F.; Younes, H.M.; El-Kadi, A.O.; Neufeld, R.J.; Amsden, B.G. Sustained interferon- $\gamma$ delivery from a photocrosslinked biodegradable elastomer. J. Control. Release 2005, 102, 607-617. [CrossRef] [PubMed]

12. Yoshii, T.; Hafeman, A.E.; Nyman, J.S.; Esparza, J.M.; Shinomiya, K.; Spengler, D.M. A sustained release of lovastatin from biodegradable, elastomeric polyurethane scaffolds for enhanced bone regeneration. Tissue Eng. A 2010, 16, 2369-2379. [CrossRef] [PubMed]

13. Guan, J.; Stankus, J.J.; Wagner, W.R. Biodegradable elastomeric scaffolds with basic fibroblast growth factor release. J. Control. Release 2007, 120, 70-78. [CrossRef] [PubMed] 
14. Pêgo, A.P.; Poot, A.A.; Grijpma, D.W.; Feijen, J. Copolymers of trimethylene carbonate and $\varepsilon$-caprolactone for porous nerve guides: Synthesis and properties. J. Biomater. Sci. Polym. Ed. 2001, 12, 35-53. [CrossRef] [PubMed]

15. Schappacher, M.; Fabre, T.; Mingotaud, A.F.; Soum, A. Study of a (trimethylenecarbonate-co- $\varepsilon$-caprolactone) polymer-Part 1: Preparation of a new nerve guide through controlled random copolymerization using rare earth catalysts. Biomaterials 2001, 22, 2849-2855. [CrossRef]

16. Fabre, T.; Schappacher, M.; Bareille, R.; Dupuy, B.; Soum, A.; Bertrand-Barat, J.; Baquey, C. Study of a (trimethylenecarbonate-co- $\varepsilon$-caprolactone) polymer-Part 2: in vitro cytocompatibility analysis and in vivo ED1 cell response of a new nerve guide. Biomaterials 2001, 22, 2951-2958. [CrossRef]

17. Song, Y.; Wennink, J.W.; Kamphuis, M.M.; Vermes, I.; Poot, A.A.; Feijen, J.; Grijpma, D.W. Effective seeding of smooth muscle cells into tubular poly(trimethylene carbonate) scaffolds for vascular tissue engineering. J. Biomed. Mater. Res. A 2010, 95, 440-446. [CrossRef] [PubMed]

18. Rocha, D.N.; Brites, P.; Fonseca, C.; Pêgo, A.P. Poly(Trimethylene carbonate-co- $\varepsilon$-caprolactone) promotes axonal growth. PLoS ONE 2014, 9, e88593. [CrossRef] [PubMed]

19. Song, Y.; Wennink, J.W.; Kamphuis, M.M.; Sterk, L.M.; Vermes, I.; Poot, A.A.; Feijen, J.; Grijpma, D.W. Dynamic culturing of smooth muscle cells in tubular poly(trimethylene carbonate) scaffolds for vascular tissue engineering. Tissue Eng. A 2011, 17, 381-387. [CrossRef] [PubMed]

20. Papenburg, B.J.; Schüller-Ravoo, S.; Bolhuis-Versteeg, L.A.; Hartsuiker, L.; Grijpma, D.W.; Feijen, J.; Wessling, M.; Stamatialis, D. Designing porosity and topography of poly(1, 3-trimethylene carbonate) scaffolds. Acta Biomater. 2009, 5, 3281-3294. [CrossRef] [PubMed]

21. Gui, L.; Zhao, L.; Spencer, R.W.; Burghouwt, A.; Taylor, M.S.; Shalaby, S.W.; Niklason, L.E. Development of novel biodegradable polymer scaffolds for vascular tissue engineering. Tissue Eng. A 2011, 17, 1191-1200. [CrossRef] [PubMed]

22. Jeong, S.I.; Kim, B.S.; Kang, S.W.; Kwon, J.H.; Lee, Y.M.; Kim, S.H.; Kim, Y.H. In vivo biocompatibilty and degradation behavior of elastic poly(L-lactide-co-e-caprolactone) scaffolds. Biomaterials 2004, 25, 5939-5946. [CrossRef] [PubMed]

23. Zhang, Z.; Kuijer, R.; Bulstra, S.K.; Grijpma, D.W.; Feijen, J. The in vivo and in vitro degradation behavior of poly(trimethylene carbonate). Biomaterials 2006, 27, 1741-1748. [PubMed]

24. Zhu, K.J.; Hendren, R.W.; Jensen, K.; Pitt, C.G. Synthesis, properties, and biodegradation of poly(1,3-trimethylene carbonate). Macromolecules 1991, 24, 1736-1740. [CrossRef]

25. Pêgo, A.P.; van Luyn, M.J.A.; Brouwer, L.A.; van Wachem, P.B.; Poot, A.A.; Grijpma, D.W.; Feijen, J. In vivo behavior of poly (1, 3-trimethylene carbonate) and copolymers of 1,3-trimethylene carbonate with D,L-lactide or $\varepsilon$-caprolactone: Degradation and tissue response. J. Biomed. Mater. Res. 2003, 67A, 1044-1054. [CrossRef] [PubMed]

26. Pêgo, A.P.; Poot, A.A.; Grijpma, D.W.; Feijen, J. In vitro degradation of trimethylene carbonate based (co)polymers. Macromol. Biosci. 2002, 2, 411-419. [CrossRef]

27. Albertsson, A.C.; Eklund, M. Influence of molecular structure on the degradation mechanism of degradable polymers: In vitro degradation of poly(trimethylene carbonate), poly(trimethylene carbonate-co-caprolactone), and poly(adipic anhydride). J. Appl. Polym. Sci. 1995, 57, 87-103. [CrossRef]

28. Athanasiou, K.A.; Niederauer, G.G.; Agrawal, C.M. Sterilization, toxicity, biocompatibility and clinical applications of polylactic acid/polyglycolic acid copolymers. Biomaterials 1996, 17, 93-102. [CrossRef]

29. Sachlos, E.; Czernuszka, J.T. Making tissue engineering scaffolds work. Review: The application of solid freeform fabrication technology to the production of tissue engineering scaffolds. Eur. Cell Mater. 2003, 5, 29-39. [PubMed]

30. Karp, J.M.; Shoichet, M.S.; Davies, J.E. Bone formation on two-dimensional poly (DL-lactide-co-glycolide) (PLGA) films and three-dimensional PLGA tissue engineering scaffolds in vitro. J. Biomed. Mater. Res. A 2003, 64, 388-396. [CrossRef] [PubMed]

31. Engelberg, I.; Kohn, J. Physico-mechanical properties of degradable polymers used in medical applications: a comparative study. Biomaterials 1991, 12, 292-304. [CrossRef] 
32. Pêgo, A.P.; Grijpma, D.W.; Feijen, J. Enhanced mechanical properties of 1,3-trimethylene carbonate polymers and networks. Polymer 2003, 44, 6495-6504. [CrossRef]

33. Bat, E.; Plantinga, J.A.; Harmsen, M.C.; van Luyn, M.J.; Zhang, Z.; Grijpma, D.W.; Feijen, J. Trimethylene carbonate and $\mathcal{E}$-caprolactone based (co)polymer networks: mechanical properties and enzymatic degradation. Biomacromolecules 2008, 9, 3208-3215. [CrossRef] [PubMed]

34. Bat, E.; Plantinga, J.A.; Harmsen, M.C.; van Luyn, M.J.; Feijen, J.; Grijpma, D.W. In vivo behavior of trimethylene carbonate and $\varepsilon$-caprolactone-based (co)polymer networks: Degradation and tissue response. J. Biomed. Mater. Res. A 2010, 95A, 940-949. [CrossRef] [PubMed]

35. Timbart, L.; Tse, M.Y.; Pang, S.C.; Amsden, B.G. Tissue response to, and degradation rate of, photocrosslinked trimethylene carbonate-based elastomers following intramuscular implantation. Materials 2010, 3, 1156-1171. [CrossRef]

36. Jansen, J.; Boerakker, M.J.; Heuts, J.; Feijen, J.; Grijpma, D.W. Rapid photo-crosslinking of fumaric acid monoethyl ester-functionalized poly(trimethylene carbonate) oligomers for drug delivery applications. J. Control. Release 2010, 147, 54-61. [CrossRef] [PubMed]

37. Jansen, J.; Bosman, M.B.; Boerakker, M.J.; Feijen, J.; Grijpma, D.W. Photo-crosslinked poly(trimethylene carbonate)-fumarate/ $n$-vinyl pyrrolidone networks for the controlled release of proteins. J. Control. Release 2010, 148, e79-e80. [CrossRef] [PubMed]

38. Song, Y.; Kamphuis, M.M.; Zhang, Z.; Sterk, L.M.; Vermes, I.; Poot, A.A.; Feijen, J.; Grijpma, D.W. Flexible and elastic porous poly(trimethylene carbonate) structures for use in vascular tissue engineering. Acta Biomater. 2010, 6, 1269-1277. [CrossRef] [PubMed]

39. Bat, E.; Kothman, B.H.; Higuera, G.A.; van Blitterswijk, C.A.; Feijen, J.; Grijpma, D.W. Ultraviolet light crosslinking of poly(trimethylene carbonate) for elastomeric tissue engineering scaffolds. Biomaterials 2010, 31, 8696-8705. [CrossRef] [PubMed]

40. Jansen, J.; Koopmans, S.A.; Los, L.I.; van der Worp, R.J.; Podt, J.G.; Hooymans, J.M.; Feijen, J.; Grijpma, D.W. Intraocular degradation behavior of crosslinked and linear poly(trimethylene carbonate) and poly(D,L-lactic acid). Biomaterials 2011, 32, 4994-5002. [CrossRef] [PubMed]

41. Yang, L.Q.; He, B.; Meng, S.; Zhang, J.Z.; Li, M.; Guan, Y.M.; Li, J.X.; Gu, Z.W. Biodegradable cross-linked poly(trimethylene carbonate) networks for implant applications: Synthesis and properties. Polymer 2013, 54, 2668-2675. [CrossRef]

42. Yang, L.; Li, J.; Meng, S.; Jin, Y.; Zhang, J.; Li, M.; Guo, J.; Gu, Z. The in vitro and in vivo degradation behavior of poly(trimethylene carbonate-co-e-caprolactone) implants. Polymer 2014, 55, 5111-5124. [CrossRef]

43. Bat, E.; Plantinga, J.A.; Harmsen, M.C.; van Luyn, M.J.A.; Grijpma, D.W.; Feijen, J. In vivo degradation of TMC and $\varepsilon$-CL(co)polymer networks. In Proceedings of the 8th World Biomaterials Congress, Amsterdam, The Netherlands, 28 May-1 June 2008.

44. Chapanian, R.; Tse, M.Y.; Pang, S.C.; Amsden, B.G. The role of oxidation and enzymatic hydrolysis on the in vivo degradation of trimethylene carbonate based photocrosslinkable elastomers. Biomaterials 2009, 30, 295-306. [CrossRef] [PubMed]

45. Tracy, M.A.; Ward, K.L.; Firouzabadian, L.; Wang, Y.; Dong, N.; Qian, R.; Zhang, Y. Factors affecting the degradation rate of poly(lactide-co-glycolide) microspheres in vivo and in vitro. Biomaterials 1999, 20 , 1057-1062. [CrossRef]

46. Chapanian, R.; Tse, M.Y.; Pang, S.C.; Amsden, B.G. Long term in vivo degradation and tissue response to photo-cross-linked elastomers prepared from star-shaped prepolymers of poly( $\varepsilon$-caprolactone-co-D,L-lactide). J. Biomed. Mater. Res. A 2010, 92, 830-842. [PubMed]

47. Karjalainen, T.; HiljanenVainio, M.; Malin, M.; Seppala, J. Biodegradable lactone copolymers. III. Mechanical properties of $\varepsilon$-caprolactone and lactide copolymers after hydrolysis in vitro. J. Appl. Polym. Sci. 1996, 59, 1299-1304. [CrossRef]

48. Storey, R.F.; Warren, S.C.; Allison, C.J.; Puckett, A.D. Methacrylate-endcapped poly(D,L-lactide-cotrimethylene carbonate) oligomers. Network formation by thermal free-radical curing. Polymer 1997, 38, 6295-6301. [CrossRef]

49. Van Wachem, P.B.; van Luyn, M.J.; Olde Damink, L.H.; Dijkstra, P.J.; Feijen, J.; Nieuwenhuis, P. Biocompatibility and tissue regenerating capacity of crosslinked dermal sheep collagen. J. Biomed. Mater. Res. 1994, 28, 353-363. [CrossRef] [PubMed] 
50. Hooper, K.A.; Macon, N.D.; Kohn, J. Comparative histological evaluation of new tyrosine-derived polymers and poly(L-lactic acid) as a function of polymer degradation. J. Biomed. Mater. Res. 1998, 41, 443-454. [CrossRef]

51. Holder, W.D.; Gruber, H.E.; Moore, A.L.; Culberson, C.R.; Anderson, W.; Burg, K.J.; Mooney, D.J. Cellular ingrowth and thickness changes in poly-L-lactide and polyglycolide matrices implanted subcutaneously in the rat. J. Biomed. Mater. Res. 1998, 41, 412-421. [CrossRef]

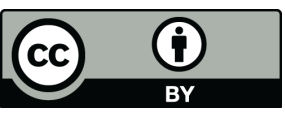

(C) 2016 by the authors; licensee MDPI, Basel, Switzerland. This article is an open access article distributed under the terms and conditions of the Creative Commons Attribution (CC-BY) license (http://creativecommons.org/licenses/by/4.0/). 